\title{
Designing Urban Squares
}

\author{
Murat Z. Memluk
}

Additional information is available at the end of the chapter

http://dx.doi.org/10.5772/55826

\section{Introduction}

The effects of fast changing economic and social conditions have increasingly become significant on how people use and shape their environments. The urban population has been dramatically increasing worldwide and consequently physical structure of the cities changes constantly, mostly in negative ways. As the population increases, the demand for infrastructure and facilities also increases. Privatization and decentralization are the two major concerns on the future of the cities and open public spaces.

Contemporary urban environment is complex in many ways. It is more heterogeneous; more multicultural and more multiethnic. Increasing mobility, communication technologies and globalization leads to expansion of urban areas causing life style changes, thus use of public spaces. Carmona groups critiques of public space issues in two categories; (i) undermanagement of public spaces, and (ii) over-management of public spaces [1]. The first group focuses on poor design and function loss of public spaces. Increasing vehicle traffic, segregation of the user groups, neglecting public space, increasing private relations of individuals are among the reasons why "public life" declines and public spaces degrade. On the other hand the second group criticizes designers and authorities for undermining "publicness" of public spaces through commodification and homogenization. However, despite there is a dichotomy in criticism of public space issues, Carmona also states "these critiques represent two sides of the same coin" [2].

Public squares are one of the significant public spaces in an urban environment. Urban squares are open public spaces which reflect the cities' identity and the communities' cultural background. They are where people of the community gather and "urban life" takes place since the ancient times. As the fundamental component of the city structure, urban squares contribute to the image and prestige of the city. According to Levy (2012), the main difference between a public park and a public square is that "on a square, citizens are not connected to manifestations of nature, but to the heart of urban culture, history and memory" [3]. In the last few decades, many urban squares have lost their function and role due to the 
changes in use of public spaces. Hence, designing urban squares as both public and open spaces now require more importance and attention.

Designing urban squares should be a part of urban design. Otherwise they become disconnected and meaningless, rather than being an integral part of the city. This chapter aims to investigate the current role and situation of urban squares and to develop design strategies in context of landscape architecture. First, I will begin with the history of public squares, and then explain the role of urban squares as open spaces. Finally, I will discuss design strategies for contemporary urban squares with design examples.

\subsection{History of public squares}

The first city formations appeared 6000 years ago and city squares were established at the crossroads of important trade routes [4].

A well-known earliest example of today's public squares is Greek's "Agora". Democracy played an important role in shaping Greek cities. The Agora was an open place in the city center where political, social and economic activities took place. Greek agoras were public spaces for all kinds of gatherings; such as political meetings, athletic and musical games, theatre performances and commercial activities [5]. The geometrical form of the agora was usually square or rectangle [6] (Figure 1).

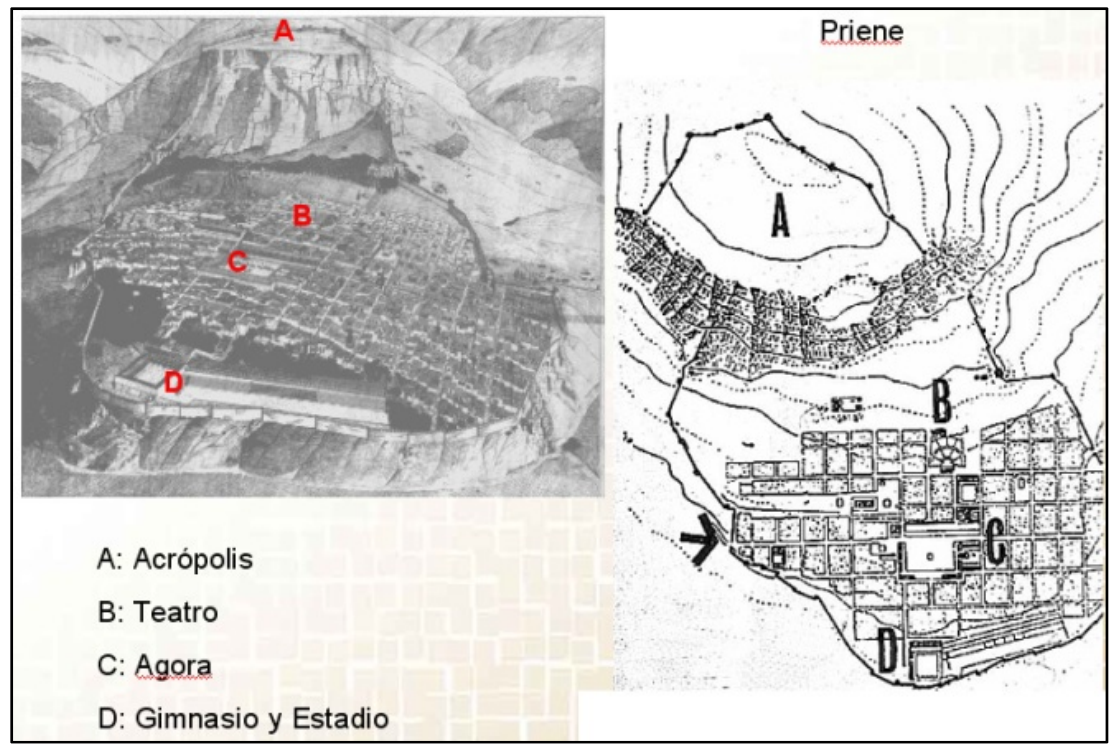

Figure 1. Agora of Priene (Aydın, Turkey) [7].

Similarly, the Roman Forum was a large open space where people gather for political, economic and social activities (Figure 2). According to Mumford (1961) the Roman forum was the combination of agora and acropolis since it included more activities (such as 
shrines, temples, the hall of justice and the council houses) with more formal order [8]. Especially, during the republican period, the forum was the heart of the city. In the last years of the Roman Empire the Roman Forum lost its importance and was used less by the public.

Following the collapse of Roman Empire, basilicas were transformed into churches and both cathedrals and churches became the focus of daily life in the middle ages. Most of the open public spaces were shaped around religious buildings. During this period commercial activities took place also in public spaces [8]. Therefore in middle ages, open public spaces were used mainly for religious ceremonies, and as marketplaces. In some European countries civic squares and piazzas emerged during this period [10].

In the neo-classical period (the Renaissance and Baroque period), there were some apparent changes in city morphology. With the changing economical, political and philosophical perspectives, approaches to planning and design of the towns shifted with the influence of rationalization during the Renaissance. Formal designs and plans were very common in this period. Symmetry and order were the essential principles in design of the squares. Italian piazzas are the very well-known examples of the Renaissance public squares. Monuments and fountains were added to the design to create aesthetically pleasant environments (Figure 3).

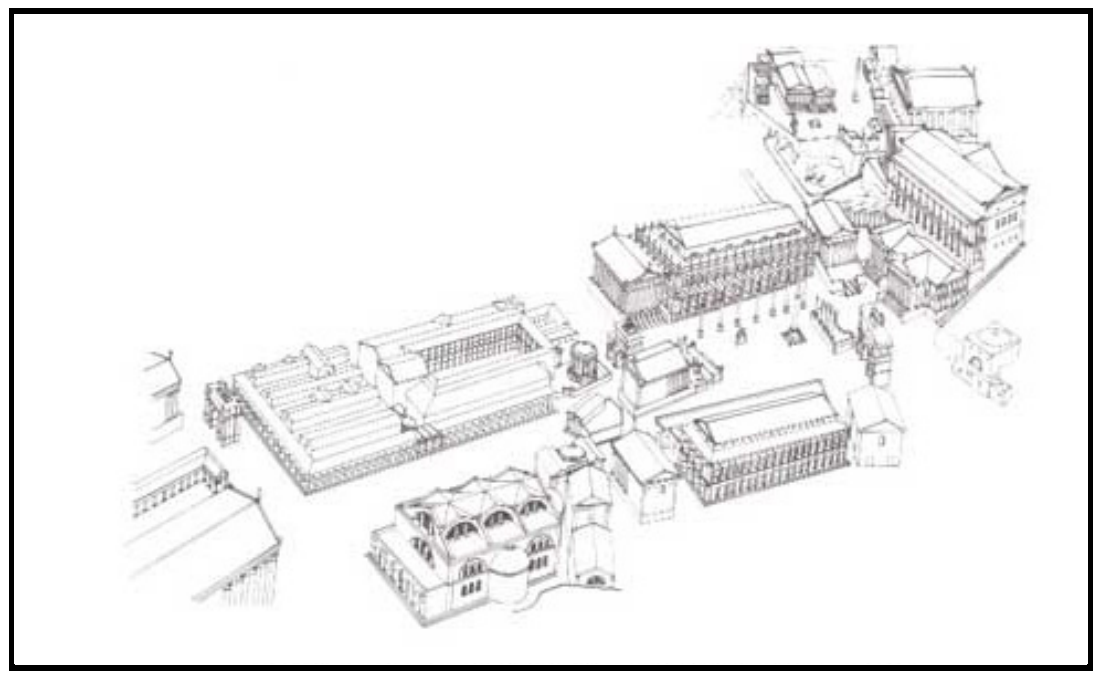

Figure 2. The Roman Forum [9].

Axial order, balance and hierarchy became main design principles during the Baroque period. In this period, open spaces were designed to create visual and ceramonial effects [6]. Piazza del Campidoglio, designed by Michelangelo, is one of the earliest examples of Baroques style open spaces. According to Zeka, the Baroque concept of "dynamic motion in space" was introduced in piazza del Campidoglio [6] (Figure 4). 


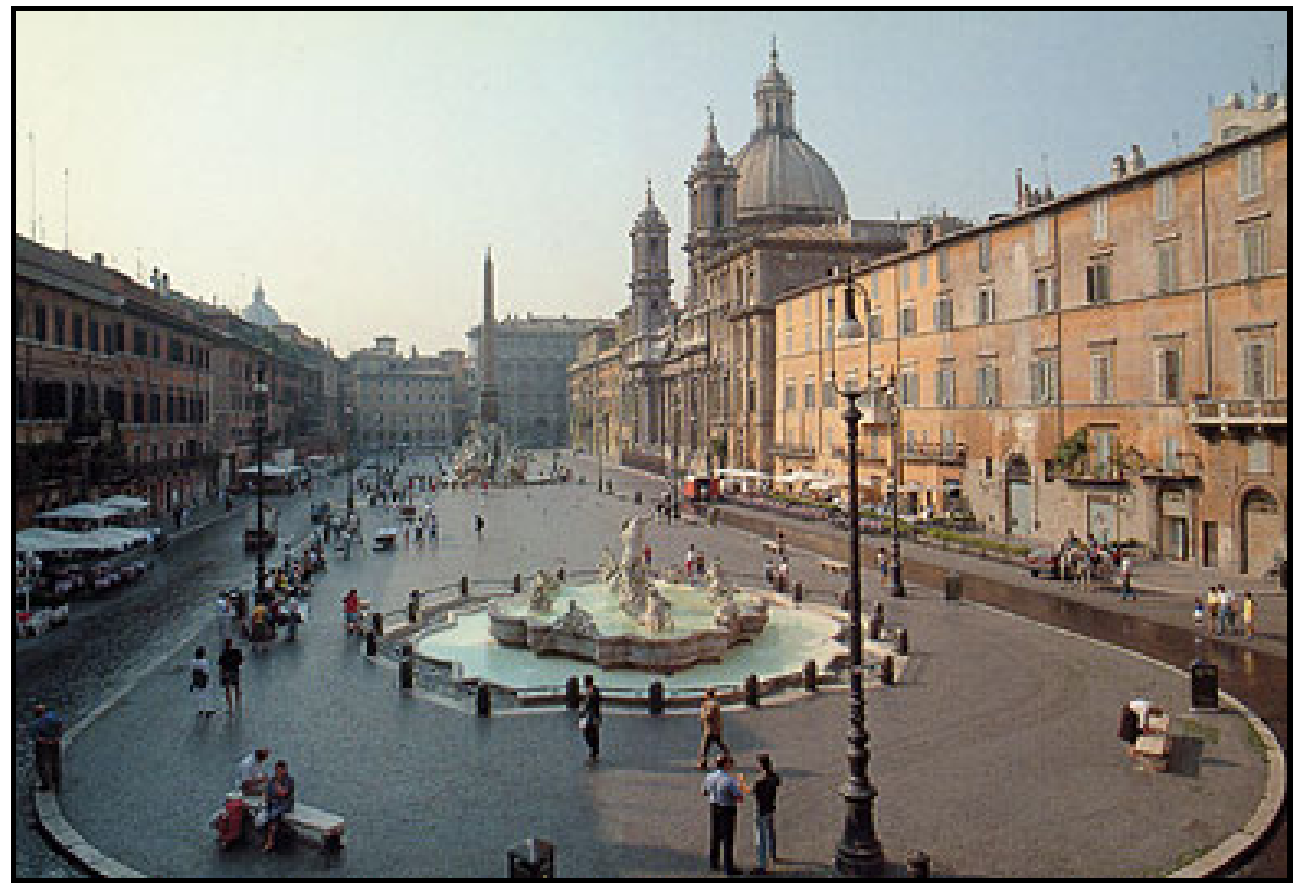

Figure 3. Piazza Navona, Italy [11].

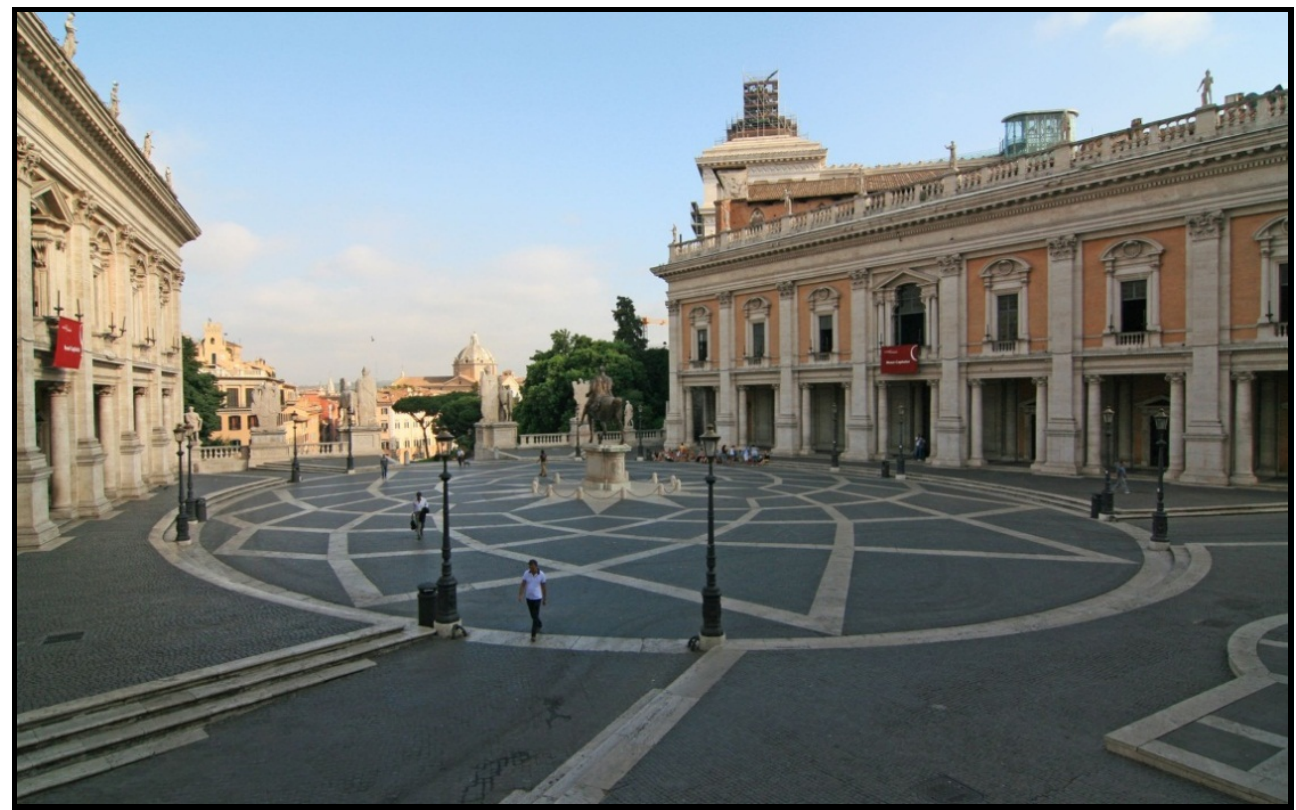

Figure 4. Piazza del Campidoglio [12]. 
In 19th century, industrial revolution caused a dramatic changes in urban design and planning. The establishment of broad railway networks leaded to population increase in urban areas which stimulated growth of cities. New industrial areas were developed near cities and labor class began to move into cities to dwell. As the bourgeoisie raised, women became more participant in the city life. The emerge of shopping arcades, shopping streets, bazaars and department stores created a new form of public space, especially for women [10]. The changing social, economical and political structure of the city also affected city morphology. Increased population meant more needs, more services and more waste. The city structure began to deteriorate. At the end of 19th century, concerns for environmental deterioration and community well-being triggered the parks movement. Instead of streets and squares, huge green areas emerged as new public places [13]. Population increase in urban areas continued during $20^{\text {th }}$ century and cities become more and more expanded, heterogeneous, and fragmented. Private automobile ownership showed a rapid increase and cities become motor vehicle dominant environments. As a result pedestrian movement and freedom were limited. In the second half of the $20^{\text {th }}$ century, many urban squares turned into crossroads especially in developing countries (Figure 5). New consumer habits and trends also caused decline in open public space use. Shopping malls have become new leisure centers. At the end of the $20^{\text {th }}$ century, following the spread of internet use, virtual environments appeared as new "social platforms".

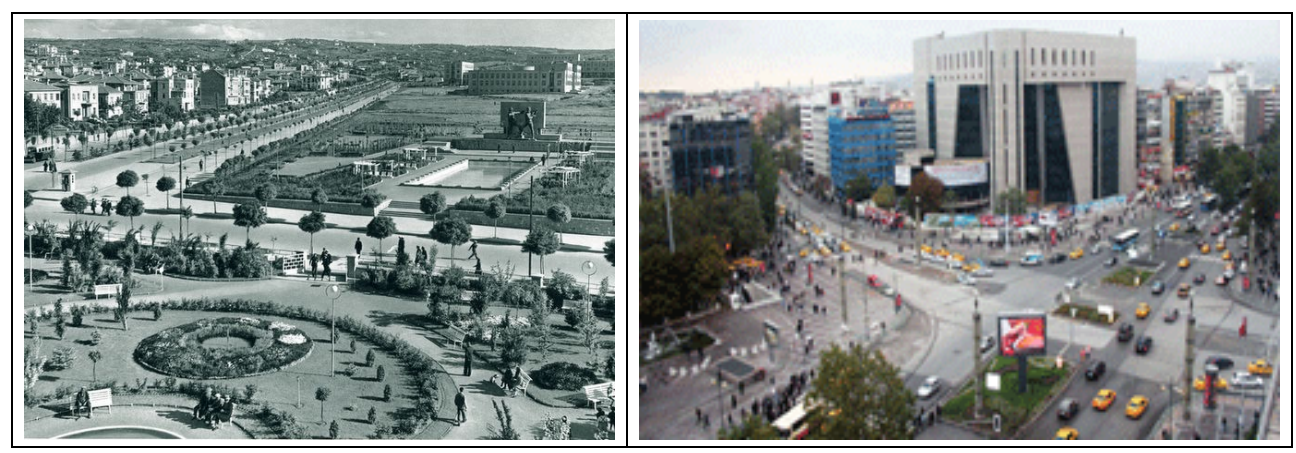

Figure 5. Left:Kızılay Square, Ankara in 1940s [14], Right: Kızılay Square, Ankara today [15].

In Islamic countries, religion has had an important influence on development and use of open public spaces. The mosque has been the centre of the social life and examples of the western style of urban squares cannot be seen in Islamic countries. Similarly throughout the history of Turkish settlements, the squares were formed around the mosques. Since markets and commercial regions were also located around mosques, these squares were where the social life took place, especially in Ottoman Empire period. Although one can easily find the traces of Roman/Byzantine influence in İstanbul's current city structure, still urban squares are located near mosques and other religious buildings. For instance, today's Sultanahmet square which was once known as hippodrome of Constantinople is surrounded by religious buildings such as Sultanahmet Mosque and Hagia Sofia Museum (Figure 6). In relatively 
smaller Anatolian cities, squares have also been used to celebrate wedding ceremonies, feasts and festivals.

During the early republican period, new urban squares were established around administrative and government buildings where national ceremonies took place. After 1950's, urbanization increased dramatically in Turkey. City centres gradually became more and more crowded and cramped with people and cars. In metropolitan areas, new city centres emerged and cities expanded uncontrollably. Political developments also influenced the use of open public spaces. During 1970s the city squares, especially in Ankara and İstanbul, witnessed many protests and gatherings of different groups of the society. However after 1980 military coup in Turkey, urban squares were transformed to "nonpolitical" and more passive places. After 1990's globalization has a massive impact on both life styles and use of public space. People have begun to prefer to spend their spare time more indoors, rather than open public spaces. As a result, Turkish urban squares have lost their importance and functions within the city, like in many other countries worldwide.

\section{Roles and functions of urban squares}

According to Lewis Mumford, primary function of cities is the acculturation and humanization of its inhabitants [17] and for these purposes public spaces are the essential tools in the city. Kostof (1992) defines some basic functions of the urban squares as [18];

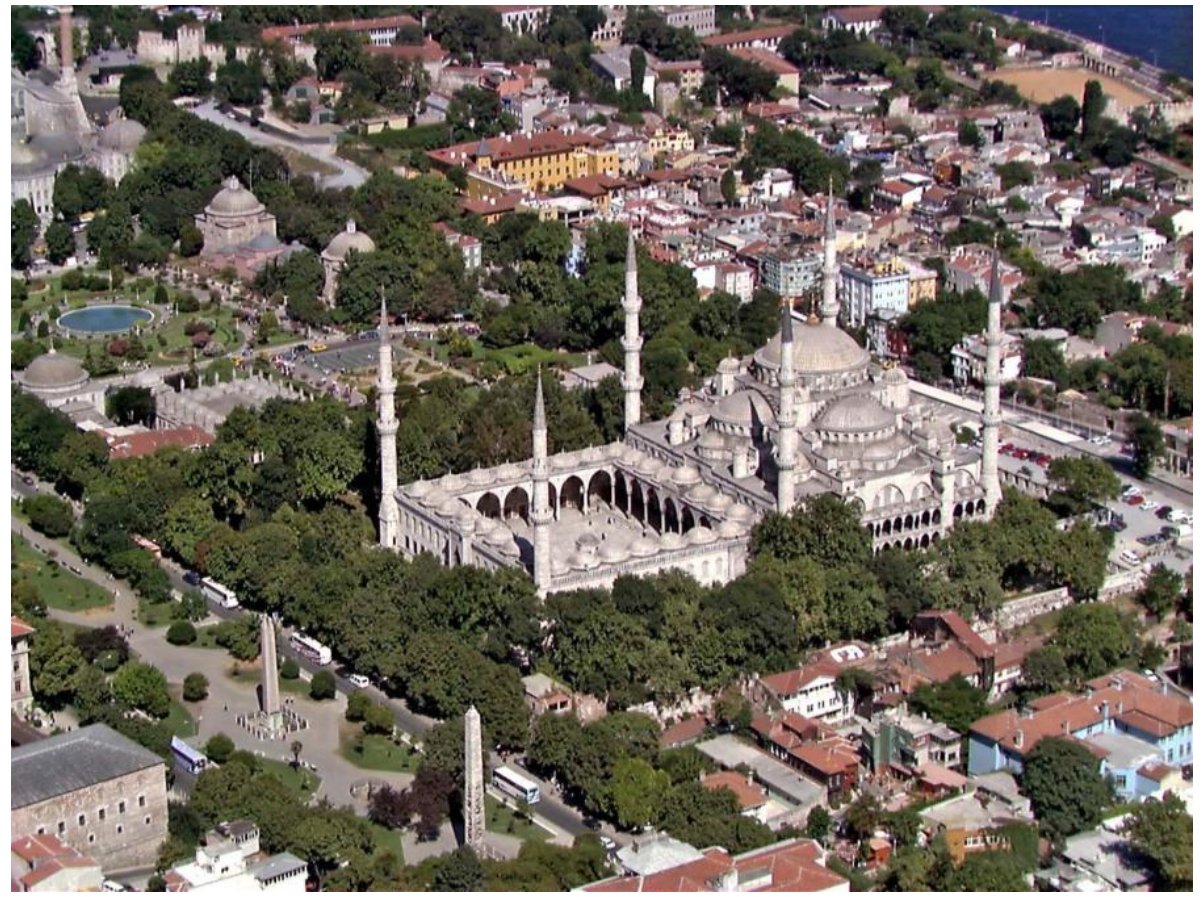

Figure 6. Sultanahmet Mosque and Sultanahmet square [16]. 
Being a part of transport system: public squares are the intersection, gathering and waiting points for both the pedestrian and vehicle traffic.

Commercial activities: public squares are civic centers where citizens engage in commercial activities. Markets have been one of the essential elements of the public squares throughout the history.

Games and sports: games and sports activities have always been an important part of public life and there have been many examples in the history where games and sports activities took place in public squares.

Kostof also believed that the links between public squares within a city forms a "system". He also stated that this approach was one of the primary issues in city planning and design during the Renaissance and Baroque periods [18].

Urban public squares are open spaces surrounded by buildings and other structures within a city. Therefore they play an important role in the context of mass and void composition of a city. Cities are formed of combination of masses and voids. The amount and ratio of masses and voids determine the structure of a city. Too many masses (e.g. buildings and structures) without connection to any voids (e.g. streets, parks and squares) would make a city cramped, illegible and chaotic. Hence, urban public squares serve as a stabilizing force especially in contemporary crowded cities.

Public squares provide citizens with places for various leisure and outdoor activities. People of the city can relax, sit, read a book, play games, meet with friends etc. in these public areas. The activities are not predefined or limited in the urban squares. Public squares can also be used for ceremonies, rituals, political activities, musical events, even theatre, and as marketplaces.

Public squares have also ecological benefits to the urban environment. Green areas and water surfaces within a square provide habitat for living organisms. Existence of green areas within a public square also helps to improve air quality, lessen surface water runoff, reduce noise levels and screen unwanted or undesirable views, and reduce negative effects of urban heat islands.

Well-designed public squares increase the visual landscape value and contribute to environmental aesthetics. While contributing to the overall city image, visual landscapes appreciated by individuals also have positive psychological impacts on the users of the place. Another psychological benefit that urban squares provide is that they are where people can relax and enjoy their spare time during their busy urban daily lives.

Urban public squares might also provide some economic benefits for the community. It is a well-known fact that existence of open and green spaces increases the real estate prices nearby [19]. Urban squares can also be used as marketplaces or they can be a part of commercial activities, such as shopping malls. There are also examples of squares where marketing is the dominating feature. Times Square in New York City is one of the wellknown examples (Figure 7). It is also one of the most famous and visited tourist attractions 
in the world. Located in Manhattan, it has a busy pedestrian traffic and density all year. Times Square also hosts various activities and ceremonies throughout the year such as annual New Year's celebrations. It is one of the landmarks of the New York City and an important part of the city image.

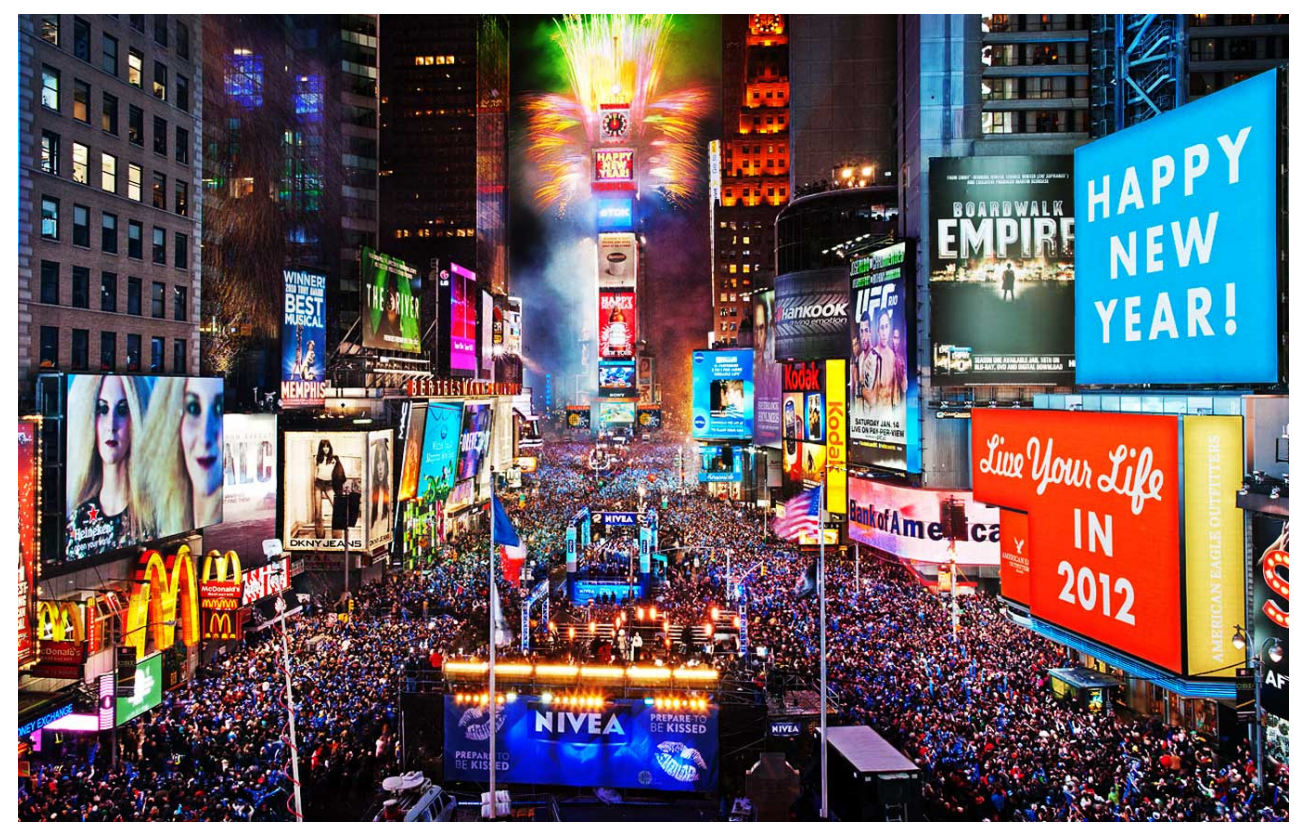

Figure 7. Times Square, New York City, USA [20].

Besides their physical and ecological roles, public squares contribute hugely to the social cohesion and local identity. They act like social catalysts. The main function of urban squares is gathering citizens together for various reasons and activities. They have a symbolic meaning of "coexistence". Hence, urban public squares are the essential elements of the city in terms of democracy. Citizens from different social, economic, and cultural backgrounds, age groups, etc. all have equal accessibility to the public spaces. Urban squares are one of these public spaces where individuals and groups learn to respect and tolerate "others". Hence, urban squares are the places where the social interaction and social cohesion occurs. The way and context of this social interaction displays the local identity. Many public squares have also historical importance for the city's identity and they usually reflect the collective values of the community.

All the roles and functions of urban public squares mentioned above also contribute to the well-being of individuals and communities. Thus, it is important to reconsider and review urban public square design approaches in order to sustain and improve our existing squares or create enjoyable new ones. 


\section{Designing urban squares}

It is quite challenging to define universal design principles that would fit for all the squares in the world. On the other hand it is possible to identify some basics that would help designers and planners through the design process. However, it is necessary to know and understand the modern city concept first. Therefore, it might be a good idea to consider the characteristics of contemporary urban environments before focusing on the design of the squares.

Today's urban environments are discontinuous, diverse and multipolar as Ascher states [21]. Changing economic and social structure, triggered by globalization, has led to expansion of urban areas uncontrollably and decentralization of cities. Globalization has been one of the significant factors that shape our physical and social environments worldwide during the last few decades. Social and spatial segregation have been increased in today's metropolitan areas because of globalization [21]. Another consequence of globalization process is that today's cities are multi-cultural and multi-ethnical more than ever. Therefore public realm is more heterogeneous today and designers and planners need to find ways to create places that serve for "everyone" in these culturally diverse communities. Finally one of the major and significant challenges of globalizing cities is the loss of identity in public spaces. Urban designers, planners and authorities should be aware of the future threats on local identity in decision making, design and planning processes.

Keeping in mind that today's urban environments are more complex and diverse, some design strategies for public squares are presented below.

Design of urban public realm involves two dimensions; functionality and visual appearance. Functionality refers to the activities and the degree of activities fitting to that place. On the other hand visual appearance is about form, image and aesthetics. While some researchers focus on the spatial arrangement of public spaces, others suggest that functionality comes first in urban space design. However, neither of them should be neglected in the design process. In fact, the relationship between these two dimensions determines the character and success of the urban space.

Many researchers have tried to identify the criteria of the ideal and successful urban space. Some of them might be useful mentioning here. For example, Carr et al. believe that public places should be [22]:

1. Responsive: a public place should serve the needs of the community; provide the citizens with spaces that allow relaxation, discovery, and active and passive engagement.

2. Democratic: Public spaces need to be accessible to all groups.

3. Meaningful: People should be able to make connections between the place, their lives and the world.

Rogers define successful public places as the places which pay dividends for cities, build civic pride, increase tourism and economic investment, and contribute to health and quality of life [23]. 


\section{Form}

A public squares form is influenced by the surrounding environment. Even though the word "square" points out a form itself, a public square can be in any form such as rectangle, square, circle, triangle or amorphous.

Camillo Sitte, in his work "City Planning According to Artistic Principles" focuses on the visual appearance rather than the functionality and defines the ideal morphologicalaesthetic criteria of the urban square as [3]:

- Enclosure; closed and protected space,

- The center should be free,

- Monuments that are placed on the perimeter,

- Existence of the elements of surprise,

- Attractiveness of architectural façades,

- Concavity and aesthetic pavement.

Sitte also emphasizes that the main requirement of a square is "the sense of enclosure" [6]. Enclosure is one of the perceptual organization principles of the Gestalt psychology. Grouping is the fundamental concept of the Gestalt approach. People tend to group objects that look similar and close to each other. Furthermore enclosure or closure helps us to perceive objects as a whole. The easiest and straightforward way of creating enclosure is grouping buildings around a central space [24].

One of the well-known works based on enclosure in the public squares is Rob Krier's work. In contrast to Sitte, Krier focused on elementary geometry when developing a typology of urban squares [24]. Krier introduces concepts of angling, segment, addition, overlapping, and distortion as modulating factors in context of urban space typology (Figure 8). According to Krier, combining these modulating factors with basic shapes of urban space (square, circle and triangle) results in either regular or irregular urban space forms [6]. Figure 9 shows some of the Krier's typologies of the urban square. On the other hand Hsu criticizes Krier's approach for ignoring the social and historical context of public squares [25].

Zucker suggests five types of urban square forms [24];

The closed square: it often has a regular geometric form. The only interruption to the closed square is the streets that are leading to it.

The dominated square: the space is directed to a building or a group of buildings.

The nuclear square: it has a central feature which creates a tension that keeps the whole together.

Grouped squares: individual squares linked organically and/or aesthetically.

The amorphous square: it is unorganized and formless when compared to other types.

\section{Location and size}

The first factor to be considered in design of urban squares is the location and the size of the square. Throughout the history squares and plazas have always been at the intersection of 


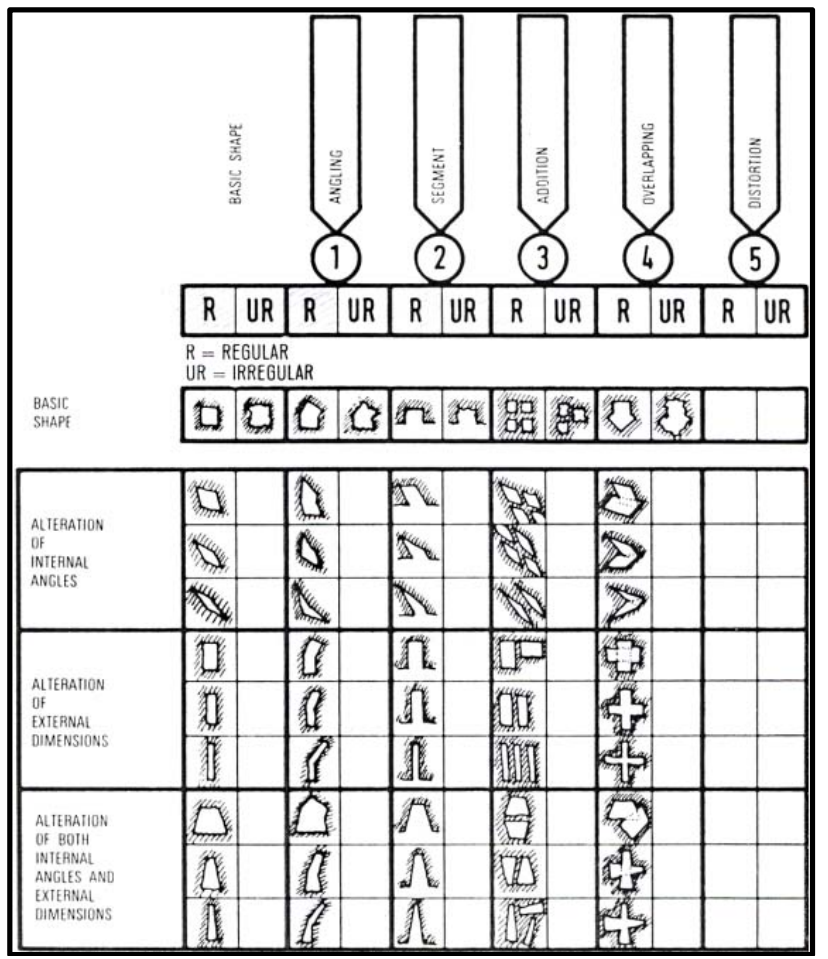

Figure 8. Modulating factors of urban space [26].

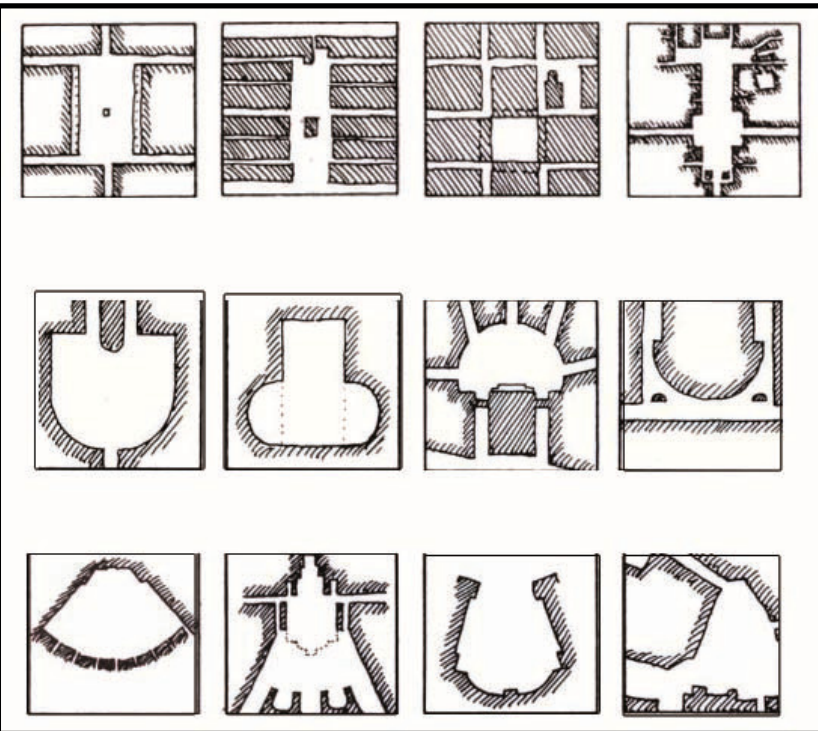

Figure 9. Some typologies of Krier's urban spaces [adopted from 26]. 
main routes of transportation and pedestrian traffic. Moreover, as Dewitte states the public squares' main function is to symbolize the archetype of human encounters and encourage urban contemplation [3] .Since human presence and activity is the essence of public squares; they should be easily accessible (both physically and visually) to public and should be created in central locations within the city.

On the other hand decentralization is one of the problems faced in contemporary cities, which makes it difficult to select central locations, since there are too many. Therefore it should also be noted that links and connections between different squares within the city should be established in order to sustain continuity of urban form.

Traditionally, squares were located next to religious and government buildings which are central to "public" life. However, as life styles change, today's cities involve many other focuses. For many, work is the central issue in our daily lives with a limited time to spare for other activities. Emerge of shopping malls also have changed/or a consequence of changing leisure patterns. Besides shopping activity, shopping malls offer many other recreational activities and facilities in one place. Therefore, people tend to prefer going to such places where they can meet their various needs in one facility. As a result, people spend their spare times more indoors than outdoors and public spaces today. There are many examples of public squares which are located around shopping malls or commercial centers/buildings in contemporary cities. Hence, designers and planners should consider the ways of bringing public squares to people when selecting the location.

Size is another aspect of urban public square design. It is often thought that public squares must be large in size. However, the size should be determined according to the location, surrounding uses, and activities nearby. The most and conventional way of determining size of a square is to calculate the number of possible users. Thus, designers and planners should focus on the "concept" of the place and possible user activity before determination of the size. Several researchers attempted to identify the ideal size of public squares. For instance according to Lynch 12 to 24 meters along each side and 100 meters for larger squares are ideal for successful urban squares, while Alexander suggests a maximum of 22 meters for small squares [6]. On the other hand Gehl suggests a dimension of 30-35 meters for the optimum size of a square in order to enable people being able to recognize the other people in the space from one side to other [27].

When determining the size of an urban square, visual perception should also be taken into account. The scale and density of the surrounding buildings and structures of a square might affect the perceived size. Squares surrounded by taller and dense buildings may appear smaller than they actually are. A ratio of 1:2 and a maximum of 1.5:2 between building height and space width can be successful to create a strong sense of definition of space [26]. Edges are also important in creating the sense of definition of an urban square. According to Alexander et al. (1977) "if the edge fails, then the space never becomes lively" [6].

\section{Activities}

Urban public squares are venues for various activities that help social cohesion and individual restoration. Generally, urban public squares are not designed to serve for any 
special type of activity. On the contrary they should be designed to provide opportunity for different kinds of activities at any time. Location and scale of a public square might also affect the activity types associated with a square. For instance, larger squares near to government buildings might be preferred to be used for protests or national celebrations by the public or squares near commercial centers might be mainly used as meeting points, performing arts venues or as marketplaces. Designers should well analyze possible user profile, their needs and expectations as well as surrounding environment's character. Some other activities might be associated with the square during design phase to attract people. For instance, nearby places to eat and drink may increase the use of space. Or placing an underground parking place might encourage people from different neighborhoods or districts using the space. However, activities aiming to attract people should never dominate the character of the square. Besides, designers should ensure involvement and participation of all social groups within a public space.

"Successful urban squares are designed for people to walk in, stand in, sit in, dance in and to perform in, and to look at other people participating in these activities" [27].

\section{Landscaping}

Generally, hard surface dominates the landscape of an urban square. Therefore selection of pavement materials is great of importance in the design phase in terms of both visual appearance and functionality. Various materials (e.g. stone, concrete, brick etc.) can be used in public square design. Pavement materials must be durable and aesthetically appealing. Durability degree of the materials can decrease or increase the maintenance costs. Surrounding architecture and streetscape should also be taken into account to ensure continuity of the character and coherence. Focal areas can be created by changing the color, form or texture, as well as pavement material itself. Similarly, by using the same strategy different uses within a square (such as seating areas) might be separated. Pavement material should be non-slippery, and suitable for walking or standing. Reflection of heat and glare should also be noted when selecting the material. Handicapped or elderly people should not be forgotten in the design phase in terms of accessibility. Drainage is another factor that should be taken into account to provide comfort in different weather conditions.

Different kinds of plants (trees, shrubs, flowers, grass etc.) can be used in the design of urban squares for different purposes such as aesthetics, shading, or visual screening. Plants also help to soften the strong and sometimes disturbing effects of hard surfaces or sharp lines. Flowering plants may also add variety to the perceived environment in terms of color and scent. Green is known for its calming and relaxing effect; hence plants might be used in order to create places for relaxation and resting. In hot climates, trees provide users with shade areas. If there is a focal point within the square like a monument, plants can be used to create a background to emphasize its visual effect. However designers should avoid using too many plants to preserve the square's main character.

Plant material should be selected based on the climate. This will reduce the maintenance costs and increase the success of plantation. There are many plants which present aesthetically pleasing and attractive changes in color and texture (like Acer species), in 
different seasons. Some trees have appealing visual effects in winter because of their geometry or color of trunks and branches, such as Betula alba and Cornus alba. Plants with poisonous fruits (e.g. Taxus baccata, Aucuba japonica, Viburnum lantana etc.) should not be used, especially within the reach of children. Plants can also be used for creating enclosure or dividing the space into subareas.

Water surfaces are landscape elements commonly used in public squares to create a focal point or aesthetically pleasing views. Water can be used in different types; as still water, running water, fountains, or combination of these. Still water surfaces create a more relaxing and tranquil environment while fountains, cascades and other running water surfaces add movement, vibrancy and dynamism to the space. For environmentally sustainable and lowcost maintenance, use of recycled water and rain-water systems should be integrated into the design. Together with lighting, water bodies and plants can be very attractive for users at night time (Figure 10).

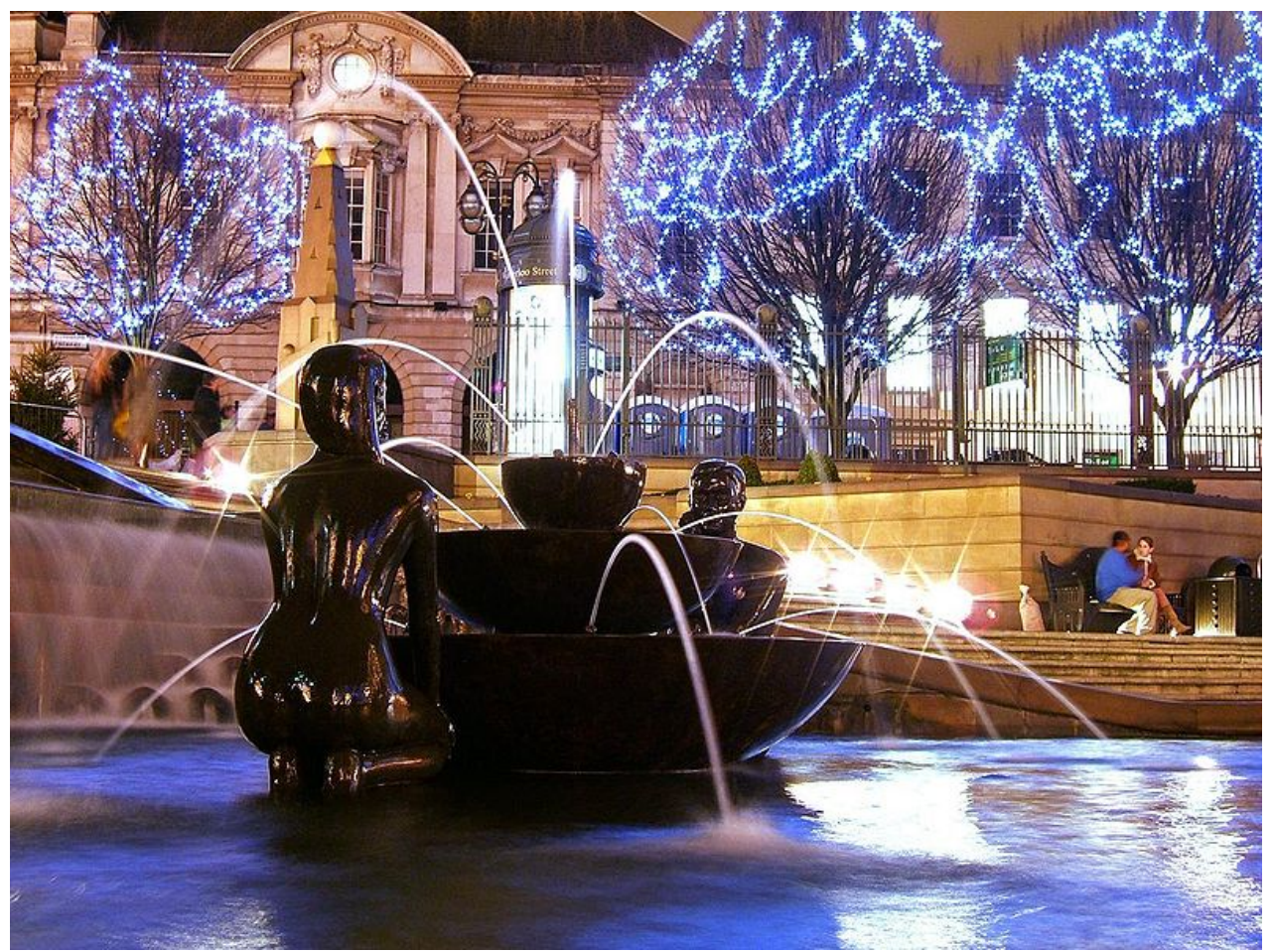

Figure 10. Victoria square, Birmingham, UK [28].

\section{Site furniture}

Seats/benches, outdoor luminaries, trash bins, direction signs are the most used site furniture items in open public spaces. Functionality comes first when selecting or designing the right site furniture. Materials used must be durable to outdoor and changing climate 
conditions. Sharp corners or edges may harm people. The surrounding architectural character should also be considered when selecting the materials and forms. Designers should avoid selecting too many different materials for different items. All site furniture should be harmonious with each other in order to provide integrity in design.

Seats can be placed either at regular intervals or as groups in different parts of the urban square. Moveable chairs or seats may make it more fun and enjoyable. They can also allow use of space for different activities at different times. Benches or seats are not necessary for providing users with a place to sit on. Walls or steps can also be used as seating places.

Seating is one of the key elements in a public square. Seating makes it possible for users to view, observe, and enjoy the environment. It also increases the users' time spent within the space. Therefore view of the space and orientation should be taken into account in the placement of seats. Seats should not be back directly to roads or passing users [27]. Designers should keep in mind that seating can act like social catalyst when well-designed. Social comfort enables spontaneous social interactions and activities [29].

Good quality lighting is necessary for users' safety and comfort at night. Lighting can also be combined with other design elements to create attractive and visually appealing environments. Direction signs should be legible and clear. Too many direction signs may cause confusion and create a chaotic environment.

Site furniture should be placed carefully and in coherence with the overall space design. Pedestrian movement and activity areas should not be obstructed. Site furniture contributes to the quality of overall design, but they should not be the dominant items in the square.

\section{Focal Point Elements}

Focal points elements might be useful to attract users while contributing to the square's identity and image. A focal point can be created by using any design element (e.g. water fountain) or public art works (e.g. sculptures, monuments). However, placing focal point elements at the center of the square is not always necessary. Sitte (1965) suggest that the centre of the squares should be kept free and focal elements should be placed along to edge, close to pedestrian routes [6].

\section{Conclusions}

Today as public spaces decline, concerns for the vitality and liveability of the cities increase. People are the main ingredients of the city and without public spaces it is impossible to establish a physical and mental connection between public and urban environment. Urban public spaces have been negatively affected by globalization and privatization. Furthermore increasing individualism has caused social fragmantation within the communities which presents itself in the changing use of public spaces. Internet has become a major component of our daily lives. Besides its economical, educational and time saving benefits, it has also dramatically changed public life. Internet has created virtual environments where people prefer to spend their time rather than going out. Social relations are necessary for the 
cohesion of communities, and local and national identity. In this context, urban public spaces are important venues for creating social relations between people.

Besides the social dimension, urban open spaces also contribute to the city image and overall quality of the physical environment. Decentralization and urban expansion are major issues in the sustainability of contemporary urban environments. If urban public spaces had not been ignored by urban designers and planners, decentralization might have been prevented to some point.

As one of the significant open public spaces, urban squares are fundamental city elements in democratic and livable cities. Therefore it is needed to recreate and design urban squares to enliven the public life and establish social cohesion. In this chapter besides the literature review, I recommended some design basics in creating successful urban public squares. Besides the physical dimension of design process, psychological aspects should also be taken into account by urban designers and planners. Physical design of urban public spaces can only be successful if safety, comfort, engagement and satisfaction of users are provided. In summary basic design principles for urban squares can be listed as:

- To create identity, sense of place and contribute to the overall city image,

- To promote public use and participation,

- To encourage social activities, communication and social integration,

- To enhance the character of the environment,

- To create a public square which is legible, enjoyable and long-lasting,

- To create both physically and socially accessible environments,

- To achieve environmental sustainability and low-cost maintenance through environmental friendly design strategies.

- To promote art, cultural activities and entertainment.

Urban public squares are more than just physical spaces; they have symbolic meaning for people. They are vibrant, active and interesting places. Most of the contemporary urban squares involve a historical value or importance for the community, as well as for the tourists and visitors. Hence, authorities should realize that urban public squares are essential for enhancing city image and community development.

Unfortunately, modern Turkey couldn't preserve many of its public squares, especially in metropolitan areas. What is now called a "square" often functions as crossroads and is occupied by vehicle traffic. Although traditional public squares in Turkish cities differ from European examples, they still have a cultural and social importance in public life. Hence, it is urgently needed to develop design and management strategies for urban public squares in order to prevent losing a vital part of the city and the community.

\section{Author details}

Murat Z. Memluk

Department of Landscape Architecture, Ankara University, Ankara, Turkey 


\section{References}

[1] Carmona M. Contemporary public space: critique and classification, Part one: critique. Journal of Urban Design 2010; 15(1) 123-148.

[2] Carmona M. Contemporary public space, Part two: classification. Journal of Urban Design 2010; 15(2) 157-173.

[3] Levy B. Urban Square as the Place of History, Memory, Identity, In : Dusica Drazic, Slavica Radisic, Marijana Simu (eds), Memory of the City, Kulturklammer, Belgrade, 2012; 156-173.

[4] www.urbansquares.com/images/resources/lecturetext.pdf, (Accessed:01.11.2012).

[5] Hölscher T. Urban Spaces and Central Places, Classical Archeology, Ed:Susan E. Alcock and Robin Osborne, Blackwell Publishing, 2007; 164-181.

[6] Zeka B. The humanistic meaning of urban squares: the case of Çayyolu urban square project. MSc Thesis, Middle East Technical University, Ankara. 2011; 241 pages.

[7] http://www.upf.edu/materials/fhuma/portal_geos/tag/t2/t2.htm, (Accessed:15.11.2012).

[8] Xing N. and Siu KWM. Historic definitions of public space: Inspiration for high quality public space. The International Journal of Humanities, 2010; 7(11) 39-56.

[9] http://courses.umass.edu/latour/Italy/RomanForum/index.html, (Accessed:13.11.2012).

[10] Ilkay Y. The political struggle on and at public space. Master of Science thesis, Middle East Technical University, 2007.

[11] http://webs.wofford.edu/davisgr/i2006/intinerary.htm, (Accessed:13.11.2012).

[12] http://unicaroma2010.it/drupal6/content/contact-us, (Accessed:13.11.2012).

[13] Sedláková M. Social Meaning of a Market on Husitská Street in Brno. Diploma Work, Masaryk University, http://is.muni.cz/th/103165/fss_m/diploma_final.pdf, Accessed:15.11.2012.

[14] http://www.sozluk.org/p/415, (Accessed:13.11.2012).

[15] http:// hurriyet.com.tr\# (Accessed:13.11.2012).

[16] The Greater Municipality of İstanbul. http://www.ibb.gov.tr/sites/ks/Gallery/IstanbulGallery/_w/sultanahmet_camii_1_jpg.jp g, (Accessed:13.11.2012).

[17] The European Square Conference Report, 2002, http://www.livablecities.org/articles/european-square-conference-report, (Accessed:13.11.2012).

[18] Büyükcivelek A.B. Meydan- Kent Meydanı (Square- Urban square). In: Ersoy M. (ed.) Kentsel Planlama Ansiklopedik Sözlük. Ankara: Ninova Publishing; 2012. p.342-344.

[19] Morris N. Health, well-being and open open space: literature review. Edinburgh College of Art and Heriot-Watt University: 2003.

[20] Times Square Alliance. http://www.timessquarenyc.org/index.aspx (accessed:01.12.2012).

[21] Hamel P. Contemporary cities and the renewal of local democracy. In: Booth P. and Jouve B. (eds.) Metropolitan Democracies: transformations of the state and urban policy in Canada, France and Great Britain. England: Ashgate; 2005. p.31-46. 
[22] Carr S., Francis M., Rivlin, L. and Stone, A. Public Space. Cambridge: University Press: 1992. 400 pages.

[23] Pasaogulları N. and Doratli N. measuring accessibility and utilization of public spaces in Famagusta. Cities 2004; 21 (3): 225-32.

[24] Carmona M., Tiesdell S., Heath T., Oc T. Public Places Urban Spaces, $2^{\text {nd }}$ Edition. UK and USA: Elsevier; 2010.

[25] Hsu B. urban Square as a Theatre: Issues of continuity and discontinuity in urban design. Master of Science Thesis. Massachusetts institute of technology: 1993.

[26] Anonymous. http://predmet.fa.uni-lj.si/siwinds/s1/u2/su1/ (accessed:01.12.2012)

[27] Anonymous. Urban Squares. 2009. Available from:

http://www.healthyplaces.org.au/userfiles/file/Development $\% 20$ type/Development $\% 20$ Type\%20-\%20Urban\%20Squares.pdf (accessed: 03.12.2012).

[28] http://en.wikipedia.org/wiki/File:Victoria_Square_at_Night.jpg (accessed 07.12.2012)

[29] http://www.pps.org/reference/generalseating/ (accessed 07.12.2012) 